\title{
O ensino de astronomia no munícipio de Cascavel/PR: um olhar para o currículo da Educação Fundamental - anos iniciais
}

\section{Rosana Maria de Oliveira ${ }^{1}$}

\section{Vilmar Malacarne ${ }^{2}$}

\section{Resumo}

O conteúdo de Astronomia tem se apresentado envolvente, instigante, altamente interdisciplinar e um importante eixo estruturante no currículo. Diante do significativo valor desse conteúdo, e por estar vinculado à disciplina de Ciências no Ensino Fundamental $\mathrm{I}$, o presente trabalho tem como objetivo verificar se o Currículo para a Rede Municipal de Ensino de Cascavel - Anos Iniciais, segue, em questões de conteúdos e metodologias, as orientações desenvolvidas pelas pesquisas científicas sobre o ensino de Astronomia. Para isso, realizou-se uma pesquisa de caráter qualitativo, enfatizando os aspectos do processo de ensino e aprendizado e as principais justificativas para esse ensino. Dos resultados obtidos, verificou-se que o Currículo não contempla algumas especificidades do conteúdo de Astronomia que são sugeridas pela literatura e a metodologia se apresenta superficial, o que compromete um aprendizado consistente.

Palavras-chave: Ensino de Ciências. Processos de Ensino e Aprendizado. Currículo Escolar.

\begin{abstract}
What content by astronomy has if presented surrounding, exciting, highly interdisciplinary and somewhat important axis structuring overall curriculum. On wards of significant value please be linked apart discipline by science overall fundamental teaching I, what gift job has goal verify if what curriculum to the web municipal by teaching by Cascavel - year homepages, following, on question by content and methodologies, pictures guidelines developed by polls scientific about what's teaching by astronomy. To that's, held a search by character qualitative, emphasizing owners aspects process by teaching and learning and pictures main justification to that teaching. From the results obtained, checked what curriculum not contemplated some specifies content by astronomy what they are suggested by the literature and methodology if superficial features, what compromises a consistent learning.
\end{abstract}

Keywords: Science teaching. Progresses by teaching and learning. Curriculum school.

\footnotetext{
${ }^{1}$ Mestranda do programa de pós-graduação em Educação em Ciências e Educação em Matemática na Universidade Estadual do Oeste do Paraná

- UNIOESTE/Campus Cascavel. E-mail: rosanaoliveira288@gmail.com

${ }^{2}$ Doutorado em Educação pela Universidade de São Paulo. É professor Associado da Universidade Estadual do Oeste do Paraná (UNIOESTE).

E-mail: vilmar.malacarne@unioeste.br
} 
Introdução

O processo de produção do conhecimento científico tem se configurado em uma Ciência que se constitui como a "[...] a forma mais eficiente de gerar conhecimento significativo no âmbito das sociedades contemporâneas" (FERREIRA DO VALE, 2009, p. 9). Nesse contexto, percebe-se a importância de disseminar a cultura científica a partir do processo de ensino e aprendizado no trabalho da educação formal.

É evidente que o Ensino de Ciências, deva ir "[...] além da transmissão dos conhecimentos científicos historicamente acumulados pela humanidade" (CASCAVEL, 2008, p. 155). E, certamente, é importante que se estabeleça entre a criança e a Ciência "[...] uma relação prazerosa com os conhecimentos relacionados aos fenômenos da natureza e da sociedade" (TRIVELATO; SILVA, 2011, p. 9), assim, os alunos sentirão satisfação em explorar, questionar, descobrir e explicar o mundo a sua volta. Diante da importância do ensino de Ciências se "[...] deve evitar a utilização de textos e/ou expressões que banalizam ou infantilizam os conhecimentos científicos" (CASCAVEL, 2008, p. 158), de modo a evitar prejuízos no processo de aquisição dos conceitos e termos essências.

A Astronomia, mesmo se caracterizando como um conteúdo puramente científico, também perpassa o campo da curiosidade, da imaginação, do deslumbramento, aspectos que podem instigar o aluno à busca pela compreensão dos fenômenos naturais e sua relação com a vida cotidiana das pessoas. Além do que, os conhecimentos sobre Astronomia estão por vias entrelaçadas ao desenvolvimento da Ciência e da Tecnologia, que se expressa, a partir de “[...] novas técnicas de produção, novos materiais e novas mercadorias" (CASCAVEL, 2008, p. 158).

Com o conteúdo astronômico presentes nos Anos Iniciais do Ensino Fundamental, compreendemos que práticas diferenciadas possam ser estratégias positivas que tendem a maximizar a aprendizagem. Além disso, esses conteúdos possibilitam estimular o desenvolvimento das habilidades cognitivas, de forma significativa e proporcionar ao aluno uma predisposição para elaboração de hipóteses. Dessa forma, percebe-se que por meio dos conteúdos, que orientam o trabalho pedagógico, é possível promover no aluno a reflexão, a criticidade e mudanças de comportamentos que terão efeitos positivos dentro do espaço social a que pertence.

A partir desses conteúdos, é possível estabelecer uma relação com o Currículo, importante ferramenta de organização das atividades pedagógicas, que tem a intenção de padronizar e disseminar os conteúdos de forma igualitária, privilegiando a todos independente de classe social, raça, cor ou etnia (CASCAVEL, 2008). A partir disso, a escola deve desenvolver seu papel no sentido de assegurar " [...] a todos a aprendizagem dos conteúdos curriculares capazes de fornecer os instrumentos básicos para a plena inserção na vida social, econômica e cultural do país" (BRASIL, 2013, p. 113).

Além de contribuir para uma formação plena do sujeito enquanto cidadão participativo e interessado nas questões relacionadas ao desenvolvimento científico e tecnológico e, por conseguinte, aos assuntos advindos dos fenômenos naturais, os quais influenciam incisivamente na vida prática das pessoas, a Astronomia expressa a curiosidade, despertando a vontade pelo conhecer em cada sujeito. 


\section{A importância do ensino de Ciências nos Anos Iniciais}

É bastante comum que o ensino de Ciências para os anos iniciais do Ensino Fundamental ocorra sob a égide da educação formal e por esse motivo se apresenta com características bastante "tradicionais". De suas características, destaca-se o esclarecimento de fenômenos, a formação de conceitos e principalmente a propagação dos conhecimentos científicos, para o qual tem se tornado comum o uso de livros e métodos memorísticos.

Este ensino, contudo, tem passado por vários movimentos de renovação, o que contribuiu para que a concepção de Ciência como "produto" fosse deixada de lado para assumir um caráter de Ciência como "processo" (KRASILCHIK, 2000).

$\mathrm{Na}$ esteira destas mudanças, a Ciência tem se constituído como um processo social e adquire significados a partir da aproximação do ensino e da aprendizagem das características proeminentes do fazer científico. Assim, a Ciência, que busca explicações para fatos oriundos de observações e de experimentações, carece que as interpretações dos fatos sejam reconhecidas e aceitas pela comunidade cientifica (TRIVELATO; SILVA, 2011).

A Ciência, por meio da tecnologia, tem estado cada vez mais presente no cotidiano das crianças, e isso tem exigido uma concentração maior de estímulos que venham privilegiar tais conhecimentos de forma positiva no ambiente escolar (LUCION; SAUCEDO, 2017). Por isso, é importante que esteja disponível, com vista ao desenvolvimento pleno do aluno:

\footnotetext{
[...] um conjunto de metodologias privilegiadas para ajudar a criança a construir e organizar sua relação com o mundo material, que as auxilie na reconstrução das suas impressões do mundo real, proporcionando-lhes o desenvolvimento de novos conhecimentos observáveis sobre aquilo que ela investiga, indaga e tenta resolver (LIMA; MAUÉS, 2006, p. 171)
}

Nesta perspectiva, o ensino de Ciências possibilita incitar o interesse do aluno pela carreira científica, de maneira a formar profissionais capacitados para produzir conhecimentos científicos e tecnológicos que contribuirão no desenvolvimento social, econômico e cultural (UNESCO, 2005).

Com este ensino, é possível levantar situações problemas interessantes, que provoquem a construção de conhecimentos de forma intencional, de modo a trabalhar com os conteúdos numa perspectiva dinâmica e assim contextualizar com o mundo em que a criança vive e brinca (CARVALHO et al., 2007). Além disso, as práticas pedagógicas devem estimular e oportunizar a disseminação das ideias através da verbalização, na tentativa de compreender os mecanismos do processo de causa e efeito dos fenômenos estudados em sala de aula (GOLDSCHIMITD, 2012).

Para que esta realidade se constitua, é imprescindível criar condições para que a criança possa predispor de seus primeiros significados de mundo associados à Ciência e, assim, contribuir significativamente para que o próprio aluno desenvolva "[...] atitudes cientificas, habilidades e competências, que só podem ser conseguidas através de uma orientação adequada e consciente" (GOLDSCHIMITD, 2012, p. 24).

Sobre atitudes cientificas, Bodenave e Pereira (2007) argumentam que estas dependem das experiências vivenciadas pelos alunos, nas quais o meio é que irá predizer o modo de ser do sujeito. Goldschimitd (2012) reforça a ideia dos autores e afirma que é necessário fomentar tais atitudes por meio da criação e instrumentalização de 
uma realidade que proporcione o desenvolvimento do raciocínio organizado, criativo e também crítico. Ainda, segundo a autora, “[...] o aluno poderá refletir sobre a natureza dos dados de seu conteúdo compreendendo o que vem a ser senso comum e o que vem a ser fato cientifico" (GOLDSCHIMITD, 2012, p. 24).

Apesar do reconhecimento da "[...] importância da democratização dos conhecimentos científicos e o papel da escola na disseminação da cultura científica, [...]” (VIECHENESKI; CARLETTO, 2013, p. 214), há ainda uma profunda preocupação quanto ao ensino de Ciências nos Anos Iniciais do Ensino Fundamental, principalmente no que se refere às práticas pedagógicas. Isso se deve ao fato de que muitos professores sentem dificuldades em promover ações que despertem no aluno o interesse por esse conhecimento (LIMA; MAUÉS, 2006).

$\mathrm{Na}$ maioria das vezes, o ensino tem se dado de forma anacrônico, fragmentado e fechado às inúmeras argumentações, questionamentos e dúvidas que surgem durante as aulas (GOULART, 2005). Para o aluno, os conceitos, teorias e leis, se apresentam desconexos e sem sentido, os quais parecem surgir como um passe de "mágica". Isso se deve aos métodos tradicionais, que muitos professores insistem em utilizar no ensino de Ciências, e que podem estar fortemente vinculados à falta de conhecimentos na área e a própria inexperiência, de modo que tais conteúdos sejam pouco explorados (GOULART, 2005).

Além disso, Colombo Jr. et al. (2012), em suas pesquisas, relatam que o ensino de Ciência tem sido pouco valorizado pelo fato de muitos professores acreditarem que para o aluno dos anos iniciais apenas a leitura, a escrita e o cálculo são essenciais e suficientes para a sua formação.

De acordo com as pesquisas de Delizoicov e Slongo (2011, p. 210), muitos professores reconhecem que “[...] necessitam de uma formação que os ajude a trabalhar a partir de temas que sejam significativos para os alunos e a problematizá-los visando despertar o interesse pelos conhecimentos das Ciências Naturais". Da mesma forma, Carvalho, et al (2007) ressalta que:

Se esse primeiro contato for agradável, se fizer sentido para as crianças, elas gostarão de Ciências e a probabilidade de serem bons alunos nos anos posteriores será maior. Do contrário, se esse ensino exigir memorização de conceitos além da adequada a essa faixa etária e for descompromissado com a realidade dos alunos, será muito difícil eliminar a aversão que eles terão pelas ciências. (CARVALHO et al., 2007, p. 6)

Dessa forma, a responsabilidade quanto ao ensino de Ciências recai sobre o professor que deve saber abordar os conteúdos de forma que os torne instigantes e atrativos.

Ensinar ciências para crianças é dar-lhes a oportunidade de melhor compreender o mundo em que vivem. De ajudar a pensar de maneira lógica e sistemática sobre os eventos do cotidiano e a resolverem problemas práticos, desenvolvendo a capacidade de adaptação às mudanças de um mundo que está sempre evoluindo científica e tecnologicamente. (NASCIMENTO; BARBOSA-LIMA, 2006, p. 2).

Para Daher e Machado (2016), o fator que contribui para o ensino de Ciências nessa fase é a curiosidade aguçada das crianças, que permite a construção de conceitos básicos sobre o mundo. Isso possibilita que a criança esteja preparada para se deparar com os inúmeros " [...] desafios presentes na sociedade, tendo condições de utilizar o que aprendem em sala de aula, em outras situações do cotidiano, bem como discutir, na escola, assuntos advindos de sua experiência" (p. 5). 
Além disso, cria condições para que a mesma criança possa relacionar os conteúdos científicos e perceber assim sua relevância no dia a dia, como é o caso dos conteúdos relacionados à Astronomia.

\section{A Astronomia para os Anos Iniciais do Ensino Fundamental}

A Astronomia é uma Ciência que há muito tempo tem intrigado e despertado grande curiosidade. Por isso, é bem provável que "[...] o céu estrelado, suas constâncias e suas variações tem estado entre os primeiros mistérios a desafiar a imaginação e a inteligência do primeiro homo sapiens" (CANIATO, s/d, p. 81).

Diante das inúmeras indagações que surgiram, e na tentativa de compreender os diversos aspectos da vida, como por exemplo, a própria existência, a origem e as leis que regem o universo, o homem passa a converter sua atenção aos elementos e fenômenos astronômicos com o intuito de buscar respostas as suas inquietações (FERREIRA; MEGLHIORATTI, s/d).

Em frente à importância de se conhecer os conceitos e a historicidade que fundamenta a Astronomia, diversos pesquisadores (CANIATO (s/d); GANZOTTI, 2008; LANGHI; NARDI, 2012; SAMPAIO; RODRIGUES, 2015, entre outros), abordam essa temática com o intuito de mostrar como esta influência é decisiva na vida social, cultural e econômica das pessoas e como está ligada ao nosso modo de vida e hábitos. Dessa forma, Langhi e Nardi (2012) justificam esse ensino,

[...] pelo fato de esta ciência participar de nossas vidas de modo intenso e inexorável: o suceder dos dias e das noites. A divisão do tempo em horas, minutos e segundos, o calendário com o ano de 365 dias, seus meses e semanas, as estações do ano, as marés, as auroras polares, e até mesmo a vida em nosso planeta - sustentada pela energia que recebemos do Sol [...] (LANGHI; NARDI, 2012, p.108).

Dada à relevância desse ensino, é possível proporcionar ao aluno não apenas a cientificidade de um estudo sistematizado, mas estabelecer uma ligação com a vida prática das pessoas, de maneira a trabalhar no sentido de apresentar de forma prazerosa a essência desse conhecimento pondo em prática o planejamento pedagógico. E é neste viés, que, destaca-se a importância da formação de professores, seja inicial ou continuada, para que os conhecimentos científicos, didáticos e metodológicos possam ser, de fato, utilizados em sala de aula, produzindo, assim, resultados positivos nesse processo de ensino e aprendizado (FONTANELLA, 2015).

O ensino de Astronomia configura-se na curiosidade demonstrada pela criança em conhecer o imenso campo de observação que é o céu. Nas palavras de Ferreira et al (2014):

\footnotetext{
O interesse das crianças acerca do céu e do universo é marcante, principalmente nas séries iniciais, momento em que as perguntas e curiosidades estão afloradas, trazendo uma maior oportunidade para os professores iniciarem uma Ciência altamente motivadora, utilizando a astronomia como fio condutor deste processo. (FERREIRA et al, 2014, p. 102)
}

Assim, a Astronomia tem se caracterizado como um elemento que promove "[...] o interesse, a apreciação e a aproximação pela ciência geral" apresentando-se como um conteúdo potencialmente interdisciplinar (LANGHI; NARDI, 2012, p.108). Além do mais, “[...] várias outras áreas do saber humano foram supridas com informações 
e inspirações provenientes da Astronomia" (LANGHI; NARDI, 2012, p.108), é o caso da física, química, biologia, história, filosofia, sociologia, além da música, poesia, literatura e diversas outras áreas.

Franknoi (1995 apud LANGHI; NARDI, 2003) destaca bem a importância dos conteúdos de Astronomia para uma aprendizagem significativa. Destas habilidades destaca-se: a capacidade de calcular, comparar, classificar objetos e eventos, além de colaborar para o desenvolvimento da comunicação, experimentação, exploração, imaginação, mediação, observação, raciocínio lógico entre outros.

Assim, o ensino de Astronomia e seus conteúdos surpreendem por ser altamente formativo contribuindo de forma expressiva na formação da criança em idade escolar.

\section{Currículo para a Rede Pública Municipal de Ensino - Anos Iniciais de Cascavel/PR}

O currículo tem se caracterizado como o núcleo que estrutura as funções da escola enquanto instituição de formação. Apesar de ser cercado de normas também é "[...] o mais politizado, inovado, ressignificado" (ARROYO, 2011). Isso explica a quantidade de documentos nacionais para a Educação que orientam o ensino. São diversas diretrizes curriculares que norteiam o trabalho pedagógico, seja para a Educação Infantil, Ensino Fundamental, Ensino Médio, Educação de Jovens e Adultos, Educação do Campo, indígena, étnico-racial ou para a formação de professores entre outros (ARROYO, 2011).

Arroyo (2011) enfatiza que a centralidade política do currículo, se deve ao destaque dado as políticas que avaliam o ensino. Segundo o autor, são políticas que ultrapassam os limites nacionais e emergem com o objetivo de verificar com cuidado a forma como o currículo é trabalhado em sala de aula, independente da escola, região, campo, município ou estado. Dessa forma, destaca-se quatro pontos que justificam essa preocupação, nacional e internacional, em avaliar minuciosamente como o ensino está ocorrendo na prática a partir das orientações curriculares.

Em primeiro lugar, está o fato do conhecimento se encontrar em um palco de profundas disputas e por se caracterizar como um importante recurso para avanços significativos nas áreas da Ciência e da Tecnologia. Contribui ainda para que se possa interpretar, refletir e compreender o contraste social e colaborar para a inserção de projetos sociais fundamentados na ideia de um viver mais digno e humano.

Em segundo lugar esta preocupação incide no fato de que a produção e a aquisição do conhecimento está fortemente associada às relações sociais e também as políticas que enaltecem a ideia de dominação e subordinação. Esta apropriação do conhecimento age como um instrumento de reconhecimentos ou de segregação de etnias, de gênero, de classe social, campo ou periferias.

Em terceiro lugar, condiz com a ideia de haver uma estreita relação entre o currículo e o trabalho docente. Isso porque "[...] em nossa tradição o currículo é o núcleo duro, sagrado, intocável do sistema escolar" (ARROYO, 2011, p. 15). Assim, a formação do professor se traduz em uma orientação para que o profissional seja fiel ao currículo, de modo que possa garantir minimamente a transmissão dos conhecimentos, tais como estão ali dispostos. De certo modo, a formação do professor não alcançará todo o conhecimento, mas deverá privilegiar os conhecimentos "[...] sistematizados e disciplinados nos currículos" (ARROYO, 2011, p. 16). Neste panorama, percebe-se que a escola, seu sistema, a sala de aula, a organização e planejamento do trabalho pedagógico giram em torno desse território. 
Em quarto lugar, essa preocupação se respalda no fato do currículo se caracterizar como um território que reúne disputas políticas da sociedade, do Estado e de suas instituições. Essa politização, segundo Arroyo (2011), tem relação com os "[...] movimentos sociais, do movimento docente e do movimento de reorientação pedagógica que acontece nas salas de aula que vem dos educadores-docentes e dos educandos" (ARROYO, 2011, p. 17). Isso significa um avanço que permeia as relações entre as dinâmicas sociais e escolares e das dinâmicas políticas e dos currículos, que irão contribuir para “[...] abrir os currículos à riqueza de experiências sociais e de conhecimentos e à diversidade de sujeitos políticos e culturais" (Idem, 2011, p. 17).

Nessa perspectiva, o currículo tem se apresentado como um importante aliado na organização do planejamento pedagógico, mas ao mesmo tempo como um instrumento regulador do Estado, que intervém com o objetivo de oferecer minimamente os conhecimentos básicos para a formação de cidadãos capazes de refletir e serem críticos às questões sociais. Para além disso, Arroyo (2011) dá ênfase na ideia de que:

\footnotetext{
Sempre que se privilegia o que ensinar e o que aprender os alunos são vistos como meros destinatários do que ensinar-aprender sejam crianças e adolescentes, jovens ou adultos as propostas pedagógicas inevitavelmente ficarão presas aos ordenamentos e sequencias dos conteúdos. A singularidade humana, formadora dos educandos será sacrificada ou reduzida à especificidade dos processos de ensinar e de avaliar. (ARROYO, 2011, p. 217).
}

Diante disso, percebe-se a importância de se transpor o ensino para além da mera transmissão de conteúdos, sendo necessário que se leve em consideração aspectos sobre a formação do homem, sensível às relações sociais e consciente do seu lugar e de seu papel na sociedade.

Sobre isso, Leontiev (1978) aborda alguns aspectos que diferenciam os elementos que implicam no processo de desenvolvimento do homem, como por exemplo, os fatores biológicos e fatores culturais, materiais e intelectuais, adquiridos a partir da história acumulada.

As concepções e contribuições de Leontiev (1978) são consideradas relevantes no meio educacional e por isso estão presentes no Currículo para a Rede Pública Municipal de Ensino de Cascavel para os Anos Iniciais, implantado em 2008, na qual se apresenta como fundamentação teórica para o mesmo.

O Currículo Municipal de Cascavel para o Ensino Fundamental - Anos Iniciais surgiu devido aos anseios de vários profissionais da rede de ensino que perceberam a necessidade de haver um currículo próprio para a educação no município. Assim, a equipe pedagógica da Secretaria Municipal de Educação-SEMED em 2004, inicia sua organização a partir de estudos e discussões. No ano subsequente, a coordenação direciona o trabalho para que todos os profissionais da rede, professores de escolas e centros de Educação Infantil, pudesse ter livre participação nas discussões (CASCAVEL, 2008).

Paralelo a isso, o Departamento de Educação da Associação dos Munícipios do Oeste do Paraná - AMOP, também organizava estudos com os diversos representantes das equipes de ensino dos Municípios do Oeste do Paraná. Esses encontros também possuíam a mesma finalidade, discutir sobre algumas concepções, com o intuito de elaborar um Currículo para a rede pública de ensino da região Oeste do Paraná. De acordo com Cascavel (2008), houve a participação de alguns profissionais nas discussões preliminares, porem no decorrer do processo, percebeu-se a importância de haver uma participação mais efetiva dos profissionais da educação do Município de Cascavel, na construção de um currículo, com isso, surge a ideia de se elaborar um currículo próprio. 
Assim, o Currículo para os Anos Iniciais do Munícipio de Cascavel, foi pensado com a finalidade de sistematizar um arcabouço baseado em pressupostos teóricos e filosóficos que tinham a finalidade de orientar o trabalho pedagógico no espaço escolar, a partir de encaminhamentos metodológicos específicos, conteúdos e avaliações. Com isso, o Currículo surge apoiado no método materialista histórico-dialético, perspectiva que reflete uma educação em que a matéria está em uma relação dialética com o psicológico e o social (CASCAVEL, 2008).

Sobre o ensino de Ciências, o Currículo explicita que este tem por objetivo socializar os conhecimentos científicos acumulados historicamente, possibilitar ao homem compreender os fenômenos naturais para a sua própria sobrevivência e apresentar as justificativas que levaram o homem a apropriar-se de tais conhecimentos (CASCAVEL, 2008). De acordo com Cascavel (2008), assim como o conhecimento cientifico, o conhecimento tecnológico também é “[...] resultado da produção historicamente acumulada e deve ser compreendido no contexto das relações sociais" (p. 156).

Dessa forma, o ensino de Ciências deve estar comprometido com uma alfabetização que vai além da convencional, deve abranger elementos de uma alfabetização cientifica e tecnológica e sob uma abordagem que articule os conhecimentos com outras disciplinas (CASCAVEL, 2008). Assim, é necessário que seja trabalhado numa perspectiva de,

[...] apropriação dos conceitos básicos e seus desdobramentos, de forma gradativa, propiciando o entendimento das leis que regem o movimento das interações e transformações da matéria e energia no processo de produção histórica da existência (CASCAVEL, 2008, p. 158).

Para tal, o Currículo define três norteadores para o ensino de Ciências: Noções sobre o Universo; Matéria e Energia - Interação e transformação (relação de Interdependência) e Meio Ambiente - Saúde e Trabalho.

No que se refere às Noções sobre o Universo, o Currículo aponta que os conteúdos relacionados, têm a finalidade de garantir minimamente ao aluno a “[...] compreensão do processo de utilização humana, [...], dos conhecimentos sobre o Universo, através de observações do espaço celeste, antes de forma primitiva e agora com modernos instrumentos" (CASCAVEL, 2008, p.159). Além disso, deve fazê-lo compreender que as observações do céu, comparações, experimentações e estudos mais aprofundados do Universo, contribuíram para que o homem desenvolvesse diferentes estratégias de sobrevivência em vários períodos da história (CASCAVEL, 2008).

No eixo Matéria e Energia: Interação e transformação (relações de interdependência), o ponto chave está em levar ao aluno compreender as especificidades que constituem esse eixo. Sobre Matéria, entende-se os materiais que constituem o Universo, são eles: rochas, água, ar ou qualquer coisa em estado de plasma, que produzam ou transmitam energia num movimento constante e cíclico. Já ao estudo da interação e da transformação tanto da matéria quanto da energia, está fortemente fundamentada no "[...] dinamismo da existência desses objetos no universo e na ação transformadora humana sobre eles" (CASCAVEL, 2008, p. 162).

Sobre Meio Ambiente - Saúde e Trabalho, o currículo compreende como "[...] o espaço utilizado pelo homem nas suas relações sociais" (CASCAVEL, 2008, p. 163). Neste eixo, prima-se por conteúdos que abordam as estreitas relações do homem com o ambiente, numa perspectiva de suprir suas necessidades de sobrevivência. Assim, os conteúdos apresentam as consequências das ações do homem sobre a natureza, que resultam na degradação do meio ambiente e interfere significativamente na saúde em virtude da lucratividade (CASCAVEL, 2008). 
De acordo com Cascavel (2008), os conteúdos correspondentes aos três eixos norteadores e devem ser trabalhados de modo a desenvolver um diálogo entre eles, em que o ensino seja voltado para um olhar mais holístico. Contudo, o eixo que articula e deve perpassar pelos demais eixos devido a sua importância, é o eixo articulador Desenvolvimento Científico e Tecnológico, pois “[...] representa a conexão da ciência com o desenvolvimento, na objetivação da produção humana enquanto satisfação das necessidades" (CASCAVEL, 2008, p. 158). De forma geral, o currículo busca compreender a importância de se desenvolver o trabalho pedagógico, na perspectiva de levar ao aluno a relativizar os proeminentes conteúdos com a própria realidade.

\section{Um comparativo entre os Conteúdos Curriculares e os Trabalhos Científicos}

Os estudos em Astronomia, no Brasil, têm ganhado destaque nas últimas décadas e isso se deve ao avanço da Ciência e da tecnologia que contribuíram para o surgimento de importantes centros que se dedicam a esse estudo.

A SAB (Sociedade Astronômica Brasileira), por exemplo, é a maior e mais importante sociedade que se atem a esse estudo no Brasil. Foi fundada em 1974, pela união de vários astrônomos brasileiros. Desde seu surgimento, a instituição tem promovido diversas reuniões anuais, como simpósios, reuniões de trabalho e encontros para discutir trabalhos científicos, além de servir como um centro de contato com órgãos que se apresentam vinculados à pesquisa em Astronomia em todo o perímetro nacional (SAB, 2018).

A SAB como instituição reconhecida e apoiada por diversos órgãos de pesquisa, como por exemplo, a CAPES (Coordenação de Aperfeiçoamento de Pessoal de Nível Superior), CNPq (Conselho Nacional de Desenvolvimento Cientifico e Tecnológico), FAPESP (Fundação de Amparo à Pesquisa do Estado de São Paulo), FAPERJ (Fundação de Amparo à Pesquisa do Estado do Rio de Janeiro e FAPEMIG (Fundação de Amparo à Pesquisa do Estado de Minas Gerais), segue objetivos de incorporar os diversos astrônomos brasileiros, zelar pela liberdade de ensino e pesquisa, pelos interesses e direitos dos astrônomos e pelo prestígio da ciência. Também visa estimular as pesquisas e o ensino de Astronomia, além de manter contato com outros institutos e sociedades similares dentro e fora do País. A SAB, também preconiza a promoção de encontros científicos, congressos especializados, cursos e conferências visando discussões e contribuições teóricas para a área de pesquisa. E, por fim, tem a finalidade de editar e divulgar boletins informativos sobre as mais variadas atividades da instituição e divulgação de assuntos relativos a Astronomia (SAB, 2018).

A SAB promove anualmente a Olimpíada Brasileira de Astronomia. É um evento que ocorre em parceria com algumas escolas e que preparam seus alunos, a partir do ensino dos conteúdos de Astronomia, para que participem desse evento. Essa preparação ocorre com base nas sugestões de conteúdos para os Anos Iniciais do Ensino Fundamental, fornecidas pela comissão de Ensino da SAB, mas frisam que essas sugestões não seguem o objetivo de determinar sobre os saberes astronômicos que o professor deva ter noção (SAB, 2018)

Sobre esses conteúdos, a SAB categoriza da seguinte maneira: Para o $1^{\circ}$ ao $3^{\circ}$ ano trabalha-se: Localização. Pontos Cardeais. A Terra como Esfera. A passagem do tempo: dias e noites. Estações do ano. Meses e Fases da Lua. Terra: o movimento aparente do céu e os movimentos da Terra. Reconhecimento de constelações e objetos celestes. Conhecimentos gerais sobre os objetos do Sistema Solar: os oitos planetas, os planetas-anões, cometas. Estrelas, buracos negros, galáxias etc. Veículos aeroespaciais: aviões, foguetes e satélites. Sondas espaciais. Os 
satélites e foguetes brasileiros. Atmosfera e sua importância para a manutenção da vida na Terra. O homem na Lua. Educação Ambiental: Cultura do "Saber Cuidar" e do "Não Desperdício". Prática dos três erres: Reduzir, Reutilizar, Reciclar. Formas e Fontes de Energia (SAB, 2018).

Para o $4^{\circ}$ ao $5^{\circ}$ ano indica trabalhar com: Localização. Pontos Cardeais, bússolas. A passagem do tempo: dias e noites, estações do ano. Meses e fases da Lua. Terra: a Terra como esfera; o movimento aparente do céu e os movimentos da Terra. Horas e fusos horários. Calendários. Fenômenos do Sol e da Luna no céu: Fases da Lua, Eclipses, Marés. Reconhecimento de Constelações e objetos celestes. Conhecimentos qualitativo dos objetos do Sistema Solar: os oito planetas, os planetas-anões, cometas, estrelas, buracos negros etc. Veículos aeroespaciais: aviões, foguetes e satélites. Sondas espaciais. Os satélites e foguetes brasileiros. Atmosfera e sua importância para a manutenção da vida na Terra. O homem na Lua. Educação Ambiental: Cultura do "Saber Cuidar" e do "Não Desperdício". Prática dos três erres: Reduzir, Reutilizar, Reciclar. Formas e Fontes de Energia. Energia Elétrica, Caminhos da energia elétrica (SAB, 2018).

Autores, como Langhi (2004), também trabalham na perspectiva de apresentar alguns conteúdos de Astronomia, que considera relevante para o ensino nos Anos Iniciais. O autor aponta "[...] um conjunto de seis conteúdos teóricos básicos e fundamentais para que o professor dos anos iniciais do ensino fundamental atue como um mediador na preparação de um alicerce sólido [...]” (LANGHI, 2004, p.147). Esses conteúdos estão relacionados, à forma da Terra, sua órbita, sua gravidade, dia e noite, fases da lua e as estações do ano, nas quais tem o intuito de conduzir o educando a construir conhecimentos que o leve a compreender tais fenômenos (LANGHI, 2004).

Além desses Langhi (2004) apresenta, um sétimo conteúdo, assinalado como emergente, a este denomina-se “Astronomia observacional". Esta se caracteriza pelo reconhecimento de constelações específicas, sua importância histórica e cultural, além da confecção e produção de telescópios refratores e refletores a custos abaixo do mercado (LANGHI, 2004).

Para Langhi (2004), é de suma importância para a formação do aluno em idade escolar, que o mesmo conheça os sete conceitos teóricos nucleares do ensino de Astronomia. Por isso, o autor denomina a este conjunto de saberes indispensáveis ao aluno, como "astronomia essencial para o ensino fundamental", tendo como pretensão permear o campo da "alfabetização astronômica".

Sobre as metodologias, que podem ser utilizadas para trabalhar os conteúdos de Astronomia, Langhi e Silva (2018), reúnem uma coletânea de relatos de professores de Ciências que superaram as angustias e as dificuldades ao ensinar os conteúdos astronômicos, nos Anos Iniciais, a partir de metodologias diferenciadas. Os autores expõem diversas metodologias utilizadas por professores durante as suas práticas de ensino, que vão desde a simples observação do céu, a olho nu, à utilização de recursos tecnológicos mais avançados como, por exemplo, softwares, Datashows, notebooks, etc. As práticas diferenciadas também se mantiveram por meio da representação do sistema solar a partir do uso do próprio corpo, assim com as órbitas desenhadas no chão do saguão da escola, onde o aluno se posiciona em um determinado ponto com o intuito de demonstrar as localizações de cada planeta. Também ressalta, a confecção de cartazes, maquetes, dramatização dos movimentos dos astros entre outros. A partir de metodologias diferenciadas para esse ensino é que a aprendizagem se dará de forma concreta.

Assim dada à importância de cada especificidade dos conteúdos de Astronomia e de metodologias para este ensino, buscamos os conteúdos apresentados pelo Currículo Municipal de Educação de Cascavel/PR, para verificar 
se há uma sintonia entre o Currículo e as pesquisas da área. Com esta perspectiva apresentamos na sequência os conteúdos de Astronomia dispostos no Currículo Municipal de Cascavel para os Anos Iniciais:

No eixo Noções sobre o Universo para o $1^{\circ}$ Ano deverão ser trabalhados os elementos relativos aos Astros: Sol (fonte primária de energia, luz e calor, astro que ilumina a Terra, a Lua e outros corpos celestes, referencial de orientação no espaço), Planeta Terra (relação com o Sol, movimento referencial e de rotação/dia e noite e suas alternâncias, nascente e poente, movimento de translação/estações do ano) e a Lua (relação Lua-Terra-Sol, movimentos e fases).

No $2^{\circ}$ Ano: Sol (fonte primária de energia, luz e calor, projeção de sombra, movimento referencial de orientação no espaço); Astros (luminosos: estrelas (Sol), iluminosos: planetas e satélites); Lua (satélite natural da Terra, movimento, fases da Lua (calendário); Planeta Terra (relação do planeta com o Sol (distância e tamanho), movimento de rotação - dia e noite, movimento de translação - as estações do ano; movimento de revolução).

Para o $3^{\circ}$ Ano os conteúdos são: História da Astronomia (noções gerais); Sistema Solar: Sol (fonte primária de energia, estrela geradora de luz e calor), composição da luz (disco de Newton), composição: matéria hidrogênio e hélio (plasma - quarto estado físico da matéria), projeção da sombra, astros luminosos e iluminados, Sol - referencial (orientação, pontos cardeais) e Planeta Terra (forma e tamanho, força da gravidade, movimento de rotação - dia e noite, movimento de translação - as estações do ano).

Para o $4^{\circ}$ ano os conteúdos de: Universo - componentes básicos (matéria e energia): Sol - Fonte Primária de luz e calor (composição, tamanho, temperatura, produção de energia, distância da Terra); Sistema Solar (estrelas, planetas, cometas, asteróides, meteoros, astros luminosos e iluminados, Sol - referencial (orientação, pontos cardeais); Planeta Terra (movimentos de rotação: dia e noite, movimento de translação: estações do ano, solstício e equinócio (diferenças da duração dos dias e das noites dependendo do local e épocas do ano), medidas padronizadas do tempo: hora, minuto, segundo, dia, mês, ano...(relacionar como os movimentos da Terra), camadas do planeta: atmosfera, litosfera, hidrosfera e biosfera, força gravitacional; Lua (movimentos, tamanho aparente relação de distância, fases da lua, influencia da Lua na biosfera - marés, calendário lunar); Eclipse Solar e Lunar e o tópico Desenvolvimento da Astronomia (satélites artificiais, instrumentos de visualização).

E, por fim, os conteúdos para o $5^{\circ}$ Ano são: Processo de desenvolvimento dos conhecimentos astronômicos (evolução dos instrumentos de pesquisa: luneta, telescópio, outros), teorias: Geocentrismo e Heliocentrismo; Desenvolvimento da Astronomia e da Astronáutica (satélite artificial, sonda, foguete, estação espacial; aspectos históricos de exploração espacial); Universo: componentes básicos (galáxias, constelações, sistema solar e seus componentes); Sol - Fonte primária de luz e calor (composição, tamanho, temperatura, produção de energia, distância da Terra, referencial de orientação: pontos cardeais, colaterais e subcolaterais, espectro solar: composição da luz, irradiação ultravioleta, luz visível e infravermelho, desenvolvimento tecnológico: laser, materiais fluorescentes e outros); Planeta Terra (tamanho, distância e forma, movimento de rotação - dia e noite, movimento de translação - estações do ano - solstício e equinócio, força gravitacional); Lua (influência da Lua na biosfera, fases da Lua e movimentos) e por último Eclipse Solar e Lunar. 


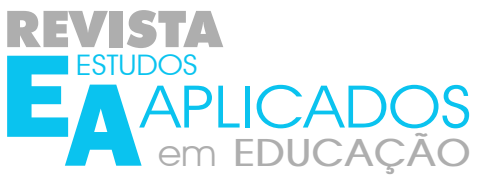

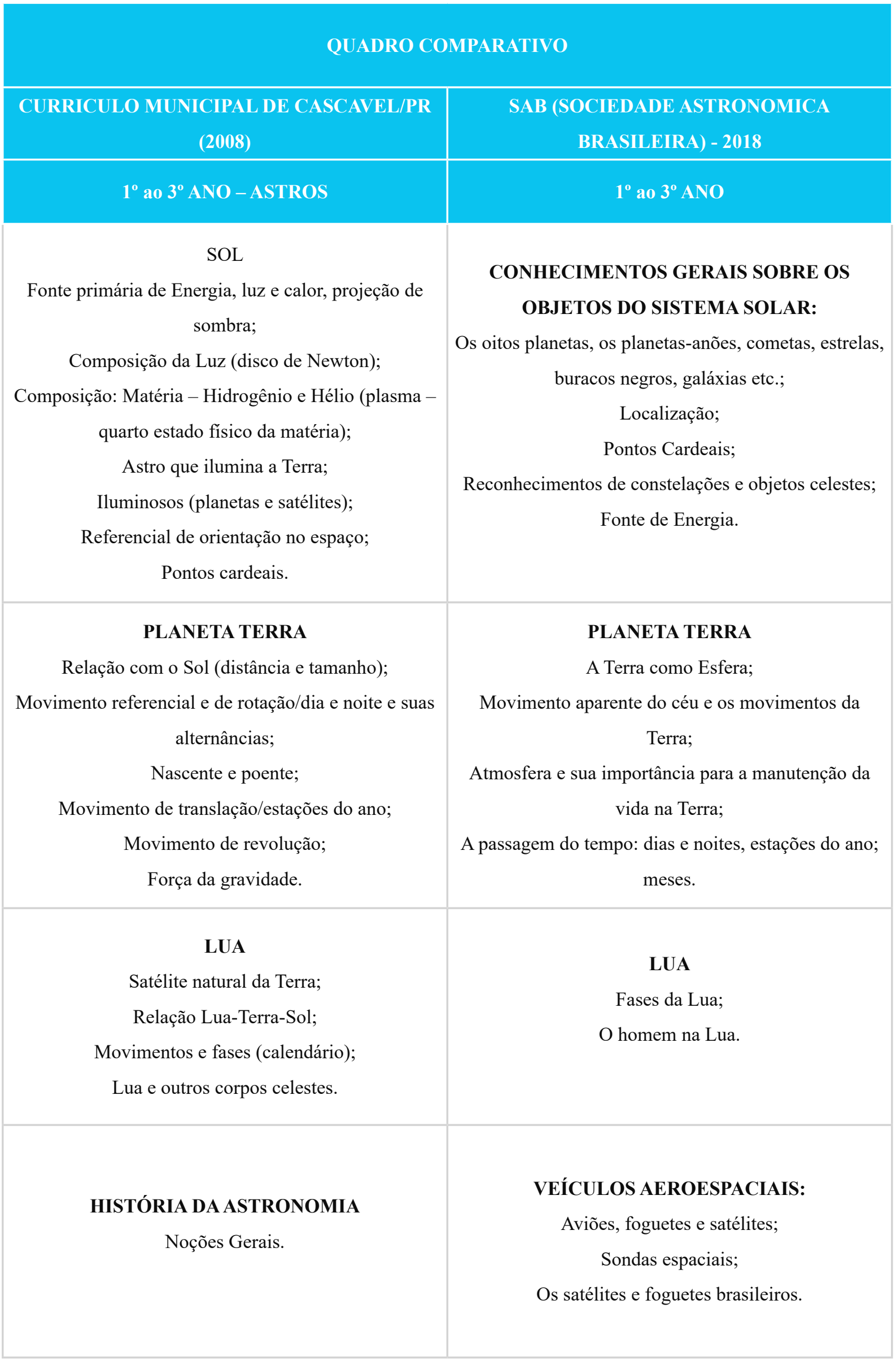




\begin{tabular}{|c|c|}
\hline $\begin{array}{c}4^{\circ} \text { ao } 5^{\circ} \text { ANO - Universo - componentes básicos } \\
\text { (matéria e energia) }\end{array}$ & $4^{0}$ ao $5^{\circ}$ ANO \\
\hline $\begin{array}{l}\text { SOL } \\
\text { Fonte Primária de luz e calor (composição, tamanho, } \\
\text { temperatura, produção de energia, distância da Terra); } \\
\text { Sistema Solar (estrelas, planetas, cometas, asteroides, } \\
\text { meteoros, astros luminosos e iluminados, Sol - } \\
\text { referencial - orientação, pontos cardeais, colaterais e } \\
\text { subcolaterais); } \\
\text { Espectro solar: composição da luz, irradiação } \\
\text { ultravioleta, luz visível e infravermelho; } \\
\text { Desenvolvimento tecnológico: laser, materiais } \\
\text { fluorescentes e outros; } \\
\text { Galáxias, constelações. }\end{array}$ & $\begin{array}{c}\text { CONHECIMENTOS QUALITATIVO DOS } \\
\text { OBJETOS DO SISTEMA SOLAR: } \\
\text { Os oito planetas, os planetas-anões, cometas, estrelas, } \\
\text { buracos negros etc.; } \\
\text { Fenômenos do Sol; } \\
\text { Reconhecimento de Constelações e objetos celestes; } \\
\text { Localização; } \\
\text { Pontos Cardeais, bússolas; } \\
\text { Fonte de Energia. }\end{array}$ \\
\hline $\begin{array}{c}\text { PLANETA TERRA } \\
\text { Tamanho, distância e forma; } \\
\text { Movimentos de rotação: dia e noite; } \\
\text { Movimento de translação: estações do ano, solstício e } \\
\text { equinócio (diferenças da duração dos dias e das noites } \\
\text { dependendo do local e épocas do ano); } \\
\text { Medidas padronizadas do tempo: hora, minuto, } \\
\text { segundo, dia, mês, ano (relacionar como os } \\
\text { movimentos da Terra); } \\
\text { Camadas do planeta: atmosfera, litosfera, hidrosfera e } \\
\text { biosfera, força gravitacional. }\end{array}$ & $\begin{array}{c}\text { PLANETA TERRA } \\
\text { A Terra como Esfera; } \\
\text { O Movimento aparente do céu e os movimentos da } \\
\text { Terra; } \\
\text { Atmosfera e sua importância para a manutenção da } \\
\text { vida na Terra; } \\
\text { A passagem do tempo: dias e noites, estações do ano; } \\
\text { meses; } \\
\text { Horas e fusos horários; } \\
\text { Calendários. }\end{array}$ \\
\hline $\begin{array}{c}\text { LUA } \\
\text { Movimentos; } \\
\text { Tamanho aparente - relação de distância; } \\
\text { Fases da lua; } \\
\text { Influência da Lua na biosfera (marés), calendário } \\
\text { lunar. }\end{array}$ & $\begin{array}{c}\text { LUA } \\
\text { Fases da Lua; } \\
\text { Marés; } \\
\text { O homem na lua. }\end{array}$ \\
\hline ECLIPSE SOLAR E LUNAR & ECLIPSE SOLAR E LUNAR \\
\hline $\begin{array}{l}\text { DESENVOLVIMENTO DA ASTRONOMIA } \\
\text { Satélites artificiais; instrumentos de visualização. }\end{array}$ & $\begin{array}{l}\text { VEÍCULOS AEROESPACIAIS: } \\
\text { Aviões, foguetes e satélites; } \\
\text { Sondas espaciais; } \\
\text { Os satélites e foguetes brasileiros. }\end{array}$ \\
\hline
\end{tabular}




\section{PROCESSOS DE DESENVOLVIMENTO DOS} CONHECIMENTOS ASTRONÔMICOS

Evolução dos instrumentos de pesquisa: luneta, telescópio, outros;

Teorias: Geocentrismo e Heliocentrismo.

\section{DESENVOLVIMENTO DA ASTRONOMIA E DA ASTRONÁUTICA}

Satélite artificial, sonda, foguete, estação espacial; Aspectos históricos de exploração espacial.

Fonte: Autores.

A partir dos dados obtidos, verificamos que tanto a literatura quanto o Currículo apontam e dão sugestões de diversos conteúdos de Astronomia para serem trabalhados nos Anos Iniciais. Dos conteúdos que a literatura sugere, estudos sobre os planetas-anões, buracos negros, recursos brasileiros como os satélites e foguetes, o homem na Lua, a Terra como esfera e bússolas não são mencionados no Currículo. Porém, verificou-se, a gama de especificidades do conteúdo astronômico presentes no Currículo e que irão privilegiar a formação do aluno desde seu ingresso no Ensino Fundamental até o término deste nível de escolarização, como por exemplo, composição da luz (disco de Newton); espectro solar: irradiação ultravioleta, luz visível e infravermelho; Desenvolvimento tecnológico: laser, materiais fluorescentes e outros; composição: Matéria - Hidrogênio e Hélio (plasma - quarto estado físico da matéria); a Terra em relação com o Sol (distância e tamanho); movimento de revolução; força da gravidade; Lua: satélite natural da Terra, relação Lua-Terra-Sol; História da Astronomia, Desenvolvimento da Astronomia: Instrumentos de visualização; processos de desenvolvimento dos conhecimentos astronômicos: Evolução dos instrumentos de pesquisa: luneta, telescópio, outros); Teorias: Geocentrismo e Heliocentrismo e aspectos históricos de exploração espacial.

Sobre a metodologia, a literatura utiliza-se de vários exemplos que poderão ajudar o professor em seu trabalho em sala de aula. O Currículo, apenas menciona, de forma genérica, que os conteúdos dispostos nos eixos Matéria e Energia: Interação e Transformação (Relações de Interdependência) e Meio Ambiente - Saúde e Trabalho, devem ser levados em consideração e consequentemente, correlacionados ao Eixo Noções sobre o Universo, pelo fato de haver uma relação de causa e efeito entre eles.

Assim, o Currículo orienta sobre a valorização das produções e que o professor deve "“...] ensiná-las de forma sistematizada" e o encaminhamento metodológico "[...] deve propiciar aos alunos a possibilidade de compreender as relações existentes entre os conteúdos" que estão dispostos nos três eixos que orientam o trabalho pedagógico (CASCAVEL, 2008, p.160). Portanto, o que se percebe é que o Currículo, ao contrário das literaturas, apresenta de forma superficial os encaminhamentos metodológicos, nas quais os professores deverão se orientar, sem haver certa riqueza de detalhes. 


\section{Considerações finais}

Os percalços sofridos pela Ciência no seu desenvolvimento ao longo da história contribuíram para que os conhecimentos adquiridos ganhassem sentidos a partir da comprovação dos fatos por meio de observações, experimentações e análises.

Atualmente, a pesquisa tem se apresentado como progenitora dos avanços científicos e tecnológicos, e tem viabilizado a resolução de diversos problemas sociais. A Ciência ganhou espaço e diante de sua relevância, no contexto das sociedades contemporâneas, e o ensino de seus conteúdos tem se tornado essencial para a formação integral do aluno em idade escolar, principalmente porque a realidade social está fortemente entrelaçada ao desenvolvimento da Ciência e da tecnologia e por isso tem se exigido o mínimo de conhecimento na área. Além disso, os conhecimentos provenientes da Ciência estabelecem uma relação com a vida cotidiana, o que se constatou ser importante para que os alunos possam ter uma ampla noção da realidade a partir de situações da própria realidade.

O conteúdo de Astronomia no ensino de Ciências tem contribuído para a ampliação dos conhecimentos prévios, pois instiga o aluno a pesquisar, explorar, experimentar, na tentativa de sanar suas inquietações em decorrência dos fenômenos naturais que ocorrem diariamente, sob a forte influência dos astros. É interessante enfatizar que esses conteúdos podem ser trabalhados a partir da simples observação ou através de atividades um pouco mais elaboradas.

O fato dos conteúdos de Astronomia prenderem a atenção dos estudantes por serem altamente ricos em detalhes e por despertar a curiosidade a partir de seus fenômenos, colabora para que, com o uso de metodologias apropriadas, estes possam se consolidar definitivamente. Por isso destaca-se a importância da formação de professores, seja inicial ou continuada, que contemple as especificidades desse ensino e que dê sugestões metodológicas para orientar o trabalho em sala de aula.

Os conteúdos de Astronomia estão inseridos no currículo de Cascavel, o que é importante por ser uma maneira de sistematiza-los. Apesar de ser um artificio estruturante com a finalidade de orientar o trabalho pedagógico, o que se pode verificar é que quando comparado com a literatura da área, alguns conteúdos astronômicos não constam em sua grade curricular, apresentando brechas que poderão não sanar algumas dúvidas em relação a este ensino. Além do mais, isso se torna preocupante quando olhamos para um conteúdo que estimula o interesse do aluno e pode ser um importante aliado na propagação dos conhecimentos científicos e na formação de futuros cientistas.

Além disso, o que também se verificou foi que neste currículo, as questões relativas aos encaminhamentos metodológicos, se apresentam de forma superficial, com poucas orientações para esse ensino, bem ao contrário daquilo que a literatura tem apresentado, a qual expõe exemplos claros de metodologias diferenciadas, que podem alcançar mais as expectativas tanto dos professores, com relação ao ensinar, quanto dos alunos, na busca por respostas.

Para fins de conclusão, o que apontamos é que este processo de comparação entre a literatura da área e um determinado currículo, é uma forma de se discutir perspectivas diferentes o que, em última instância, colabora na superação de lacunas no processo de ensino e de aprendizagem dos conteúdos. 
Referências

ARROYO, M. G. Currículo, território em disputa. 2. ed. Petrópolis: Editora Vozes, 2011.

BODENAVE, J. D.; PEREIRA, A. M. Estratégias de Ensino de aprendizagem. 28. ed. Rio de Janeiro: Vozes, 2007.

BRASIL. Ministério da Educação e Cultura. Programas do MEC voltados à formação de professores. 2013. Disponível em: http://portal.mec.gov.br/index.php?option=com_content\&view=arti cle\&id=159:programas-do-mec-voltados-a-formação-de-professores. Acesso: 15 ago. 2018.

CANIATO, R. Astronomia e Educação. Universo Digital: Liga Ibero-americana de astronomia, s.d., p.80-91.

CARVALHO, A. M. P. et al. Ciências no ensino fundamental: o conhecimento físico. São Paulo: Scipione, 2007.

CASCAVEL (PR). Secretaria Municipal de Educação. Currículo para a Rede Pública Municipal de Cascavel: volume II: Ensino Fundamental - anos iniciais. Cascavel, PR, 2008.

COLOMBO, Jr. P.C.; LOURENÇO, A.B.; SASSERON, L. H; CARVALHO, A. M. P. Ensino de física nos anos iniciais: análise da argumentação na resolução de uma atividade de conhecimento físico.

Investigação no Ensino de Ciências (Online), v. 17, p. 489 - 507, 2012.

DAHER, A. F. B.; MACHADO, V. de M. Ensino de Ciências nos Anos Iniciais do Ensino Fundamental: o que pensam os professores. VI Enebio e VIII Erebio Regional 3. Revista da SBEnBio - Associação Brasileira de Ensino de Biologia, n. 9, 2016.

DELIZOICOV, N. C.; SLONGO, I. I. O ensino de Ciências nos anos iniciais do Ensino Fundamental: elementos para uma reflexão sobre a prática pedagógica. Série-Estudos Periódico do Programa de Pós-graduação em Educação da UCDB. N.32 (jul-dez de 2011).

FERREIRA DO VALE, J. M. Educação Científica e Sociedade. In: NARDI, R. (Org.) Questões Atuais no Ensino de Ciências. São Paulo, Escrituras Editora, 2009.

FERREIRA, D.; MEGLHIORATTI, F. A. Desafios e Possibilidades no Ensino de Astronomia. Cadernos do PDE. Cascavel, s.d.

FERREIRA, G. T. A.; OLIVEIRA, K. A.; OLIVEIRA, L. M. Importância da Astronomia nas Séries Iniciais do Ensino Fundamental. Revista Extendere. v. 2, p. 101-110, 2014. Disponível em: periodicos.uern.br/index.php/extendere/article/view/1291/734. Acesso em: 23 fev. 2018.

FONTANELlA, D. Ensino de Astronomia: Investigando a Formação Docente em um Espaço não Formal. 125 f. Dissertação (Mestre em Educação). Programa de Pós-Graduação em Educação pela Universidade Estadual do Oeste do Paraná- UNIOESTE. Cascavel, 2015.

GANZOTTI, S. E. M. Um Curso Introdutória a Astronomia para a Formação inicial de 
Professores de Ensino Fundamental, em Nível Médio. 260 f. Dissertação (Mestre em Ensino de Física). Instituto de Física da UFRGS. Porto Alegre, 2008.

GOULART, C. As Práticas Orais na Escola: o seminário como objeto de ensino. 228 f. Dissertação (Mestrado em Linguística). Instituto de Estudos da Linguagem (IEL) da Universidade Estadual de Campinas (UNICAMP). UNICAMP, 2005.

GOLDSCHIMIDT, A. I. O Ensino de Ciências nos Anos Iniciais: sinalizando possibilidades de mudanças. 226 f. Tese de Doutorado (Programa de Pós-Graduação em Educação em Ciências: Química da Vida e Saúde. Universidade Federal de Santa Maria - UFSM/RS. Santa Maria, 2012.

KRASILCHIK, M. Reformas e realidade: o caso do ensino das ciências. São Paulo em Perspectiva, 14 (1), 2000, p.85-93.

LANGHI, R. Um estudo exploratório para a inserção da Astronomia na formação de professores dos anos iniciais do Ensino Fundamental. Dissertação (Mestrado em Educação para a Ciência). Faculdade de Ciências. Unesp, Bauru, 2004.

LANGHI, R.; NARDI, R. Um Estudo exploratório para a Inserção da Astronomia para a Formação de Professores dos Anos iniciais do Ensino Fundamental. IV Encontro Nacional de Pesquisa em Educação em Ciências. p. 1-7, Bauru, São Paulo, 2003. Disponível em: http://abrapecnet.org.br/ enpec/iv-enpec/orais/ORAL171.pdf. Acessado em: 19 de fevereiro de 2018.

LANGHI, R.; NARDI, R. Educação em Astronomia: repensando a formação de professores. São Paulo: Escrituras, 2012.

LANGHI, R.; SILVA, S. R. da. Astronomia na educação Infantil e nos Anos Iniciais do Ensino Fundamental: relatos de professores. São Paulo: Editora Livraria da Física, 2018.

LEONTIEV, A. N. O desenvolvimento do psiquismo. Lisboa: Livros Horizonte, 1978.

LIMA, M. E. C. de C.; MAUÉS, E. Uma releitura do papel da professora das séries iniciais no desenvolvimento e aprendizagem de ciências das crianças. Ensaio - Pesquisa em Educação em Ciências, v.8, n.2, dez. 2006.

LUCION, J. D.; SAUCEDO, K. R. R. O Ensino de Ciências na Educação Infantil: um estudo da produção acadêmica de teses e dissertações em Educação. In: MALACARNE, V.; STRIEDER, D. M. (Org.). O Ensino de Ciências e Matemática: Concepções e práticas. São Leopoldo: Trajetos Editorial, 2017.

NASCIMENTO, C.; BARBOSA-LIMA, M. C. O ensino de física nas séries iniciais do ensino fundamental: lendo e escrevendo histórias. Revista Brasileira de Pesquisa em Educação em Ciências (RBPEC), v 6, n. 3, 2006.

$\mathrm{SAB}$ - Sociedade Astronômica Brasileira. Olimpíada brasileira de astronomia. Disponível em:<http://www.oba.org.br.; Acesso em: 15 ago. 2018. 
LANGHI, R.; NARDI, R.. Sociedade Astronômica Brasileira. Homepage que apresenta dados sobre a instituição. Disponível em :<http://www.sab-stro.org.br/historico.html.; acesso em: 15 de junho de 2018.

SAMPAIO, T. A. de S. M.; RODRIGUES, E. da S. Método Didático para o Ensino de Astronomia: utilização do software Stellarium em conjunto com aulas expositivas no ensino médio. C\&D Revista Eletrônica da Fainor, 8, p.87-97, 2015. Disponível em: http://srv02.fainor.com.br/revista/ index.php/memorias/article/viewFile/426/249. Acesso em: 23 fev. 2018.

TRIVELATO, S. F.; SILVA, R. L. F. Ensino de Ciências. Coleção Ideias em ação. São Paulo: Cengage Learning, 2011.

UNESCO BRASIL. Ensino de Ciências: o futuro em risco. 2005. Disponível em: http://unesdoc. unesco.org/images/0013/001399/139948por.pdf. Acesso em: 01 jun. 2011.

VIECHENESKI, J. P.; CARLETTO, M. Por que e Para quê Ensinar Ciências para Crianças. Revista Brasileira de Ensino de Ciências e Tecnologia, v. 6, n. 2, mai-ago.2013.

Recebido em: 05/12/2018

Aprovado em: 29/04/2019 